\title{
Preparing Undergraduate Students for IT Certification
}

\author{
Akram Al-Rawi, Faouzi Bouslama, and Azzedine Lansari \\ College of Information Systems, Zayed University \\ Abu Dhabi, UAE
}

\author{
akram.alrawi@zu.ac.ae faouzi.bouslama@zu.ac.ae \\ azzedine.lansari@zu.c.ae
}

\begin{abstract}
Current demand for Information System (IS) graduates requires that they master specific technical skills needed by industry and government institutions. Revising the IS curriculum to keep it up to date while meeting demands of the Information Technology (IT) labor market continues to be a challenging task. In order to graduate students that are competitive, post-secondary educational institutions must adopt a new methodology where IT certification is an integral part of the IS curriculum. The IEEE and ACM recognize the importance of IT certification and provide its members with over 800 online courses that lead to various IT certificates. The selection of the appropriate IT certificate for integration into the IS curriculum is a complex task as it entails a thorough knowledge of the curriculum and the certificate objectives. The goal of this paper is to propose a selection of IT certificates which can be readily integrated into the IS curriculum. Three potential certification tracks for the purpose of this study are identified: Networking, Programming, and IT hardware and software. A list of vendors and non-vendors IT certificates and their exam requirements is developed, and the IS courses which can lead to the listed IT certificates are identified. This identification is based on matching specific course objectives with the IT certificate and the timeline needed for the certificate completion. The selection of the IT certificates for each track is optimized to facilitate both student learning and the completion of the certificate. Integrating IT certification in computing curricula makes IS programs more attractive to students. Moreover, the acquisition of IT certification is a valued asset for graduates seeking employment or advancement in the computing field.
\end{abstract}

Keywords: Information Systems, IT certifications, Curriculum design, IS courses.

\section{Introduction}

Certification establishes a standard of competency in specific area and job roles (Montante \& Khan, 2001). This helps industry to determine that employees meet the required credentials for

Material published as part of this publication, either on-line or in print, is copyrighted by the Informing Science Institute. Permission to make digital or paper copy of part or all of these works for personal or classroom use is granted without fee provided that the copies are not made or distributed for profit or commercial advantage AND that copies 1) bear this notice in full and 2) give the full citation on the first page. It is permissible to abstract these works so long as credit is given. To copy in all other cases or to republish or to post on a server or to redistribute to lists requires specific permission and payment of a fee. Contact Publisher@InformingScience.org to request redistribution permission. different jobs roles thus requiring less training during the initial employment period. Hence, some job criteria require individuals to be certified in order to be considered for employment. To the certified individual, certification provides a greater sense of confidence in their abilities and a measure of professional expertise and understanding of the job role and products used in that role. It is for these reasons that certification is be- 
coming increasingly popular and in high demand. Many training companies are providing certification-training classes at high costs all across the globe. Unlike traditional academic degrees, some certificates are specific to narrow fields or even to individual products. The aim is to provide targeted skills that have immediate applicability in the workplace.

Cisco, Microsoft, Sun, Novel, Oracle, and other vendors offer certification programs for their own products and related job roles. Third-party companies around the world provide certificatetraining classes for these vendors and, increasingly, offer certifications of their own that are venders neutral. Academic institutions, from vocational and technical schools to large universities, are beginning to provide similar training in their curricula to prepare students for certification in special areas (Peterson, Morneau, \& Saad, 2003). This paper presents ideas for making changes to the existing IS curricula so that courses would help students prepare for certifications in areas such as Networks, Java programming, Hardware and Software, and Internet Technology.

\section{Certification Consensus}

There appears to be a consensus in the community about the importance of certification (Tripp, 2002; Cantor, 2002). In a 2001 IEEE Computer Society survey of software engineering professionals, more than $70 \%$ of the respondents agreed that certification would fill a need for improving the software engineering profession and that a software engineering certification program could be used to improve the engineering workforce. More than $67 \%$ agreed that certification helps assess an individual's software engineering knowledge and skills. While the role of certification is primarily for the public benefit, individual practitioners may also benefit. The participants in this survey were given a list of eight possible benefits of certification and asked to pick up to three that would best describe the benefits to an individual software engineering practitioner. More than $80 \%$ of respondents felt that certification provides recognized evidence of professional capability. Two-thirds felt that certification helps assess an individual's software engineering knowledge and skills, while 44 percent felt that it leads to greater professional recognition. Individuals may also seek certification for personal benefits such as increased opportunity for upward mobility, better ability to compete in the job market, and increased professional credibility, although these benefits were much lower rated by respondents.

In the same survey, respondents identified the benefits of certification to an employer hiring a practitioner. The highest ranking was given to the statement that certification provides confidence in a standard set of knowledge areas with which the individual will be familiar. Employers may also view certification as a means for improving job performance and rewarding employees. Employers may also find that training certified employees take less time. Although the survey targeted software engineering certification the same argument is true for any other IT certification.

\section{Motivation to Include IT Certification in IS Curricula}

Certification can be defined as an indicator or confirmation of a person's adequate knowledge and skills in a specified occupation or a particular specialty in that occupation. Certification can be classified into two categories: Vendor specific certification, such as Cisco CCNA or Microsoft MOS, and certification issued by vendor neutral organization or professional associations such as CompTIA and ECDL. Some certificates such as the one issued by Cisco are generally issued for a defined period of time after which there is a need to pass another series of examination to demonstrate continued competency. Other certifications such as the ones issued by CompTIA do not have an expiration date.

Increasingly, employers are turning to certifications as a means to ensure that prospective employees actually do have the required skills for an occupational specialty (Koziniec \& Dixon, 2002; Zeng, 2004). Employers are asking educational institutions to incorporate certification 
exam opportunities into their programs as a further way for students to demonstrate the necessary workplace skills, along with their diplomas. On the other hand, students find that certifications can be earned in a much shorter time period than full associate degree programs take, and that certification often leads to higher starting salaries. There are a numbers of reasons that drive the need to include IT certification as a critical component of IS/IT curricula. A rapid change in workplace technology requirements has increased the burden on workers and employers to maintain workplace skills and to document worker competency. Training students for the workforce and providing them with cutting edge IT skills needed to compete in college education is driving administrators to implement IT certification programs. Students are attracted to colleges that teach leading edge technologies and provide avenues to acquire IT certifications. Employers have a tendency to hire graduates that have acquired IT certification in addition to their degree. Currently University and colleges that offer IT certification often separate IT certification objectives from their undergraduate curricula. It is however important to include IT certification objectives into key IS courses in order to provide an opportunity for students to acquire certification upon completion of these courses.

\section{Certificates That can be Integrated into IS Curricula}

There are many IT certificates which can be integrated into various IS curricula. Some of these certificates are vender neutrals such as CompTIA's A+, Network+, i-Net+, and Security+. Other certificates are associated with certain manufacturer such as Cisco CCNA and CCNP. Cisco academy also offers courses that lead to non Cisco certificates such as A+ and Sun Certified Programmer for Java 2. Microsoft also offers a lot of certificates starting from a simple certificate such as MOS to a more complicated certificate such as MCSE. Here, we will address some of the most popular certificates and how they can be integrated into a well established IS curriculum. The proposed IS curriculum is based on the IS 2002 model curriculum, as shown in Figure1.

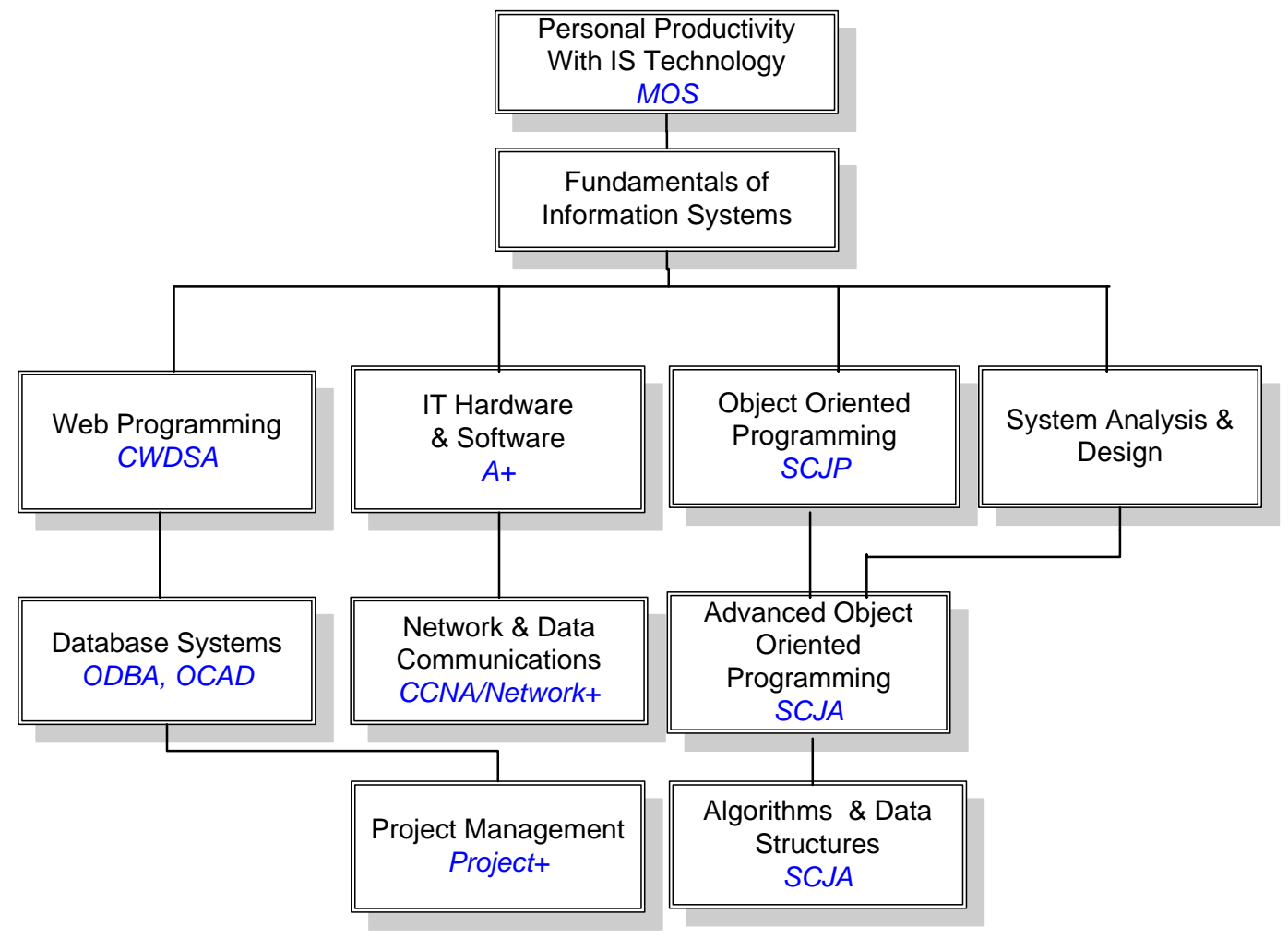

Figure 1: Implementation of the IS 2002 core curriculum with respective IT certificates 
Such a curriculum has been developed to fulfill the ABET requirements for accreditation. The IS 2002 model curriculum includes 33 credit hours of IS core courses while a typical degree requires 120 to 126 credit hours. To address the needs of industry for IS graduates to acquire certification the IS 2002 model curriculum is strengthened by including IT certification tracks. Faculty and College administration can provide various tracks to strengthen their IS curriculum. For example a networking track will include courses which lead to MOS, CCNA and possibly CCNP certification; a programming track may include courses which lead to MOS, SCJP and SCJA; a web developer track may include course which lead to the MOS, CWDSA, i-Net+, and Project+; a database administrator track would include courses which lead to the MOS; ODBA and OCAD; and an IT hardware and software track which could lead to the MOS, A+, Network+, and i-Net+. The following certificates are investigated briefly for possible integration into an IS course.

\section{A+ Certificate}

A+ certificate is a CompTIA-sponsored testing program that certifies the competency of entrylevel computer service technicians. There are two different A+ exams that lead to certification. One exam focuses on Core Hardware and the other on OS Technologies. These tests cover a broad range of technologies but are not vendor-specific. The two exams cost $\$ 318$. A+ certification signifies that the certified individual possesses the knowledge and skills essentials for a successful entry-level computer service technician. The A+ test is available globally in a variety of languages through testing centers, which are listed on the CompTIA website at http://www.CompTIA.org. The Cisco Networking Academy's IT Essentials I: PC Hardware and Software course helps to prepare students to take both of the exams necessary for this certification. Cisco press also publishes a textbook and a lab manual for this course. Community colleges in the US and Devry University offers a course which prepare students for the A+ certification exams. However, they do not have a mechanism to make the student take the certification exam. IS 2002 (Gorgone, Davis, Valacich, Topi, Feinstein, \& Longenecker, 2002) model curriculum has a core course called IT Hardware and System Software (IS 2002.4). This course can be used to integrate the A+ certificate and typically it requires four to five semester hours. Cisco curriculum for this course includes 70 hours of instruction plus a lab component. Besides Cisco textbook and lab manuals there are few textbook from course technology and one textbook from Sybex that can be used for this course. However, one of the main features of our method of offering this course is that in order to pass the course the student must pass the certification exam. This requirement insures that the student has actually mastered the needed skills to pass the course and has also acquired the credentials to show competency at an international level by passing the certification exam.

\section{Network+ Certificate}

Network+ Certification is a CompTIA-sponsored testing program, which examines an individual's networking skills. This certification is intended for entry-level network professionals. The Network+ certification certifies that the successful candidate knows the layers of the OSI model, can describe the features and functions of network components and has the skills needed to install, configure, and troubleshoot basic networking hardware peripherals and protocols. The Cisco Networking Academy Program's CCNA1 through CCNA4 helps to prepare students to take the Network+ exam. The test is currently available globally in different languages. However, the CCNA1 through CCNA4 curriculum is designed to cover the objectives of CCNA certificate. Course Technology and Sybex has a textbook that can be used to teach the certificate (Dean, 2004; Grice, 2004). IS 2002 model curriculum has one core course in Networking and data Communications (IS 2002.6) and this course can be used to integrate this certificate. The course can be covered in a 4 semester hour course which has a lab component. The lab component requires few PC's with networking interfacing cards, hubs, switches, and networking operating systems 
such as Windows 2003 server, Linux, and AppleTalk. There is a single exam for the certificate which consist of 60 multiple-choice question and the cost of the exam is \$218. Community colleges in the US offer a course to help the student achieve Network+ certificate. However, they do not require the student to take the certification exam.

\section{Server+ Certificate}

Server+ Certification is a CompTIA sponsored testing program that deals with Industry Standard Server Architecture (ISSA) issues, such as RAIDS, SCSI, multiple CPUs, SANs - and more. The level of complexity is above that of the fundamentals of a PC, making the A+ certification a good pre-cursor to Server+. This certification is geared toward mid to upper level technicians responsible for server hardware maintenance. There is one exam, which covers an in-depth understanding of planning, installing, configuring and maintaining servers, including knowledge of server-level hardware implementations, data storage subsystems, data recovery and I/O subsystems. Interrelationships of all parts of the server systems and the transmissions of their actions are also covered. The Cisco Networking Academy Program's IT Essentials II: Network Operating Systems along with IT Essentials I: PC Hardware and Software will help prepare students to take the Server+ exam. The certificate objectives can be integrated in one IS elective course. Course Technology offer textbooks on Server+ and Sybex offer reference book. A course technology textbook (Conrad, 2002) can be used to integrate this certificate in one IS elective course. The exam fee for the certificate is $\$ 218$.

\section{Linux+ Certificate}

Linux + Certification is a CompTIA sponsored testing program, which measure foundation-level Linux operating system proficiency. This certification is appropriate for individuals who are interested in demonstrating fundamental Linux knowledge and skills. The exam covers basic installation, operation and troubleshooting services for the Linux operating system and hardware on workstations and servers. System administration basics are also part of the Linux+ learning objectives. The Cisco Networking Academy Program's Fundamentals of UNIX along with IT Essentials II: Network Operating Systems will help prepare students to take the Linux+ exam. There are no prerequisites for this certification; however, CompTIA recommends the possession of $\mathrm{A}+$ and Network + certifications. The cost of the exam is $\$ 218$ and it consists of multiple-choice questions and covers six domains, these are:

- Installation

- Management

- Configuration

- Security

- Documentation

- Hardware

The certificate objectives can be integrated into a single IS course such as UNIX Operating Systems. Course Technology provides several textbooks for this certification, among them one which can be used to integrate the certification objectives into an IS course (Eckert \& Schitka, 2005).

\section{Project+ Certification}

Project+ certification is a vendor-neutral credentials recognized worldwide for the management of IT projects. The Project+ was transferred from the Gartner Institute to CompTIA in February 2001, and upgraded in November 2003. The Project+ designation is achieved by passing one conventional exam that covers best practices in project management methods and processes, criti- 
cal business knowledge and important interpersonal skills. Project+ focuses on people skills much more than the usual technical certification programs. Soft skills incorporated include conflict resolution, negotiation, communication, team building/leadership and setting and mapping expectations. It is also a core requirement for the Novell CNE certification. Sybex has a study guide reference book developed for this certificate. Course Technology also has several reference books from the ILT series. However, this series can be used to study the certificate objectives but can not be used as a textbook. The exam consists of 80 multiple-choice questions and the time allowed is 90 minutes and it cost $\$ 218$. The exam objectives cover four domains, these are:

- Project Initiation and Scope Definition

- Project Planning

- Project Execution, Control and Coordination

- Project Closure, Acceptance and Support

IS 2002 model curriculum includes one course called Project Management and Practice (IS 2002.10). This course can be used to integrate the Project+ certification objectives.

\section{Sun Certified Programmer for Java2 Platform (SCJP)}

Sun Certified Programmer for Java 2 is a Sun Microsystems certification covering the basic syntax and structure of the Java programming language. The current edition of the SCJP exam is based on the Java2 platform, version 1.5. In general, this exam is fairly comprehensive examination of one's knowledge of the latest version of the Java programming language and of few key packages that belong to the Java standard library. It covers concepts, reserved words and language structures and capabilities as well as elements of the standard Java programming environment. Some basic understanding of object-oriented design, development, testing and implementation is absolutely essential for prospective exam candidates. Specifically, these are the seven topics evaluated in this exam:

- Declarations, Initialization and Scoping

- Flow control

- API Contents

- Concurrency

- OO Concepts

- Collections/Generics

- Fundamentals

The CX-310-055 SCJP exam may be taken in any authorized Prometric testing center. It's a multiple choice and drag and drop exam, comprised of 72 questions that must be answered in 175 minutes or less. In order to pass, the candidates must correctly answer at least 43 of the 72 questions (59\%). Sun sell the exam voucher for $\$ 150$ then you need to schedule an appointment at a Prometric testing center, and the certificate is valid for a certain period of time. Cisco Networking Academy Program offers a course called Fundamentals of Java Programming which is designed to prepare the student for this certificate. Sun Microsystems offer three courses in Java to prepare students for this exam. http://www.sun.com/training/certification/objectives/index.html

The IS 2002 model curriculum include one core course in programming and problem solving (IS 2002.5). However, this certificate can not be integrated into a single Java programming course unless the student has taken another course in Object Oriented programming. It can be integrated into a 5 credits hour course in Java or two regular courses such as CS1 and CS2. Ortize (2003) 
indicated that they offer the certification as an elective course after taking CS1 and CS2 in Java. However, ideally it can be integrated in a second course in Java, and passing the certification exam is a requirement to pass the course. Standard textbook in problem solving using Java does not address all the certification objectives. Mughal \& Rasmussen (2000) address the certification objectives, however, this book is not designed as a textbook instead it can be used as a reference in conjunction with another textbook such as Farrell (2006).

\section{Sun Certified Associate for the Java Platform}

The Sun Certified Associate for the Java Platform certification exam provides an ideal entry into an application development or a software project management career using Java technologies. This worldwide credential validates basic knowledge of Object Oriented Concepts, UML representation of $\mathrm{OO}$ concepts, the Java programming language, and general knowledge of Java Platforms and Technologies. The current version of the exam is CX-310-019 and cost $\$ 100$. The exam consists of 51 multiple choice/drag and drop questions, the passing score is $68 \%$, and the exam time is 115 minutes. The exam objectives includes eight topics, these are:

- Fundamental Object-Oriented Concepts

- UML Representation of Object-Oriented Concepts

- Java Implementation of Object-Oriented Concepts

- Algorithm Design and Implementation

- Java Development Fundamentals

- Java Platforms and Integration Technologies

- Client Technologies

- Server Technologies

Sun Microsystems offer three online courses to prepare students to pass the certification exam. This certificate cannot be integrated into the first Java programming course of the IS curriculum. It can be integrated into the second course of Object-Oriented programming using Java. Java How to Program (Deitel \& Deitel, 2005), covers all the eight topics which are included in the certification objectives. However, this textbook is not dedicated for this certificate, and a search for textbook rather than a reference book is required.

\section{CCNA Certificate}

The Cisco Certified Network Associate (CCNA) certification indicates a foundation in and apprentice knowledge of networking for the small office/home office market. CCNA certified professionals can install, configure, and operate LAN, WAN, and dial access services for small networks (100 nodes or fewer), including, but not limited to, use of these protocols: IP, IGRP, IPX, Serial, AppleTalk, Frame Relay, VLANs, RIP, Ethernet, Access Lists. The Cisco Networking Academy Program's CCNA1 through CCNA4 helps to prepare students take the CCNA exam. The certificate can be taken with a single two hours exam that costs $\$ 125$, or taking two separate exams that each cost $\$ 100$ and can be taken at a Prometric or Pearson VUE testing center worldwide. Both course technology and Sybex offer textbooks that can be used to teach this certificate. While Cisco Networking Academy has an excellent curriculum for CCNA1 through CCNA4, but it requires four semesters to complete. It also requires some Cisco equipment such as routers and switches that is part of the Cisco Networking Academy Program. The other alternative is to buy the Cisco equipment and teach the CCNA course with out using the academy. This option is more practical and it can be done in one or two semesters rather than four. A textbook such as (Hudson, Caudle, \& Cannon, 2003; Cannon, 2003) can be used for this certificate. This certificate can be 
integrated into IS 2002.6 course (Networking and Data communications) and it requires 5 semester hours.

\section{CCNP Certificate}

The Cisco Certified Network Professional (CCNP) certification indicates advanced knowledge of networks. With a CCNP, a network professional can install, configure, and operate LAN, WAN, and dial access services for organizations with networks up to 500 nodes, including, but not limited to, these protocols: IP, IGRP, IPX, Async Routing, AppleTalk, Extended Access Lists, IP RIP, Route Redistribution, RIP, Route Summarization, OSPF, VLSM, BGP, Serial, Frame Relay, ISDN, ISL, X.25, DDR, PSTN, PPP, VLANs, Ethernet, Access Lists, 802.10, FDDI, Transparent and Translational Bridging.

While CCNA curriculum is more on academic, the CCNP curriculum move toward real world networking problems. Cisco Academy offers four courses, CCNP1-CCNP4, to prepare the student for the CCNP certificates. This certificate can be integrated into a networking track or into an Associate degree in networking. Students or professional who does not have access or the patient to go through Cisco Academy can also prepare for this certificate. Though Cisco Academy requires four courses to cover the CCNP curriculum, it can be integrated into two Networking courses. Sybex also has a reference guide that can be used for this certificate. This certificate requires four exams (642-801, 642-811, 642-821, 642-831).

\section{i-Net+ Certificate}

i-Net+ Certification is a CompTIA-sponsored testing program, which examines an individual's Internet technology skills. This exam covers a wide range of material about Internet, from using the Internet to demonstrating how the Internet works, using different Internet protocols, programming on the Internet, the Internet infrastructure, security, and e-commerce. Though this certificate can be taught in a single 3 semester hour course but it can be taught only in an elective course geared toward this certificate. Part of the topics addressed in this certificate is pure networking materials such as the OSI model of networking. While the other part is associated with web programming, and it covers wide range topics of both server side and client side programming. The exam consists of 74 multiple-choice questions, the passing score is 665/900 and the exam time is 90 minutes. The exam cost is $\$ 218$ and it can be taken at any Prometric or PearsonVUE testing center. Both course technology (Andrews, 2005) and Sybex have textbooks for this certificate, however, the author found the Sybex reference guide (Groth \& McGee, 2002) is an excellent one. This certificate is also recommended by the ACM task force for a K-12 model curriculum in computer science (Tucker, Deek, Jones, McCowan, Stephenson, \& Verno, 2003). INet + certifies an entry level professional by providing baseline knowledge in six areas:

- Net basics

- Net clients

- Development

- Networking and infrastructure

- Net security

- Business concepts

\section{MOS Certificate}

The Microsoft Office Specialist (MOS) is an IT certificate that measures and validates skills in the MS Office suite. The MOS certificate objectives can be easily integrated into the personal productivity with IS Technology course (IS 2002.P0), which is a prerequisite course in the IS 
2002 model curriculum. IS 2002.P0 emphasizes personal productivity concepts using functions and features in computer software such as spreadsheets, databases, presentation graphics and web authoring. This course requires prior elementary knowledge of word processing, spreadsheet, email, and web browsing. The IS 2002.P0 objectives can integrate the objectives of the MOS certificate which include the mastery of Microsoft Word, Excel, Access, PowerPoint, and Outlook. The MOS offers various levels of expertise including: Master, Expert and Specialist. The master certification requires the candidates to successfully complete three required exams (Word 2003 Expert, Excel 2003 Expert, and PowerPoint 2003) and one elective exam (either Access 2003 or Outlook 2003). Course technology publishes several textbooks which can be used for this certificate such as Shelly/Cashman (Shelly, Cashman, Pratt, \& Last, 2006) series which include modules in Word 2003, Access 2003, Excel 2003, Power Point 2003 and Outlook 2003. Each module comes in three different editions: Introductory, Complete, and Comprehensive. They consist of three, six, or nine projects. The Master certificate requires four modules, two comprehensive and two complete. Microsoft Office Specialist exams are not offered by Pearson VUE or Prometric. The MOS exams are performance based, and require the test-taker to perform specific tasks rather than multiple choice questions and each exam has a fee of $\$ 75$. The MOS master exam objectives include the following domains:

\section{Word 2003 Expert}

- Formatting Content

- Organizing Content

- Formatting Documents

- Collaborating

- Customizing Word

\section{Excel 2003 Expert}

- Organizing and Analyzing Data

- Formatting Data and Content

- Collaborating

- Managing Data and Workbooks

- Customizing Excel

\section{PowerPoint 2003}

- Creating Content

- Formatting Content

- Collaborating

- Managing and Delivering Presentations

\section{Access 2003}

- Structuring Databases

- Entering Data

- Organizing Data

- Managing Databases 


\section{Certified Web Designer Associate (CWDSA)}

The World Organization of Webmasters (WOW) has created a certification for Certified Web Designer Associate/Apprentice (CWDSA). The certification exam measures fundamental competencies for aspiring or practicing Web designers. The examinee must demonstrate knowledge of Internet concepts, HTML and WYSIWYG editors, Web graphics, Web multimedia, Web site design, Web site management, and basic legal issues. The exam contains 70 multiple-choice questions and the time for the exam is 60 minutes. The passing score may lead to an Associate (70\%) or to an Apprentice (50\%). Cisco Networking Academy offers a course, the fundamentals of Web design, sponsored by Adobe Systems, to help students to take this certification exam. The certificate can be integrated into one IS course. The WOW organization delivers the exam in partnership with public libraries nationwide (in the US). The certification exam includes the following domains:

- Internet Basics

- Web Multimedia

- HTML and CSS

- HTML and WYSIWYG Editors

- Web Graphics

- Web Site Design

- Web Site Management

- Legal Issues

\section{Discussions and Recommendations}

After examination of a number of well-known IT certificates, it was found that most of the CompTIA certificate objectives can be easily mapped and covered into specific courses of the IS curriculum. The Cisco Networking Academy also offers courses that can lead to non Cisco certificates. For example, some courses are designed to lead to the CompTIA A+ certificate. The library of certificates provided by Microsoft is very large. One recommended IT certificate from Microsoft is the MOS, which may be taken by undergraduate students in a general education course.

While Cisco Networking Academy requires their instructor to be certified in the courses they teach, community colleges and universities do not require their faculty to be certified in order to teach a certification course. Ideally, the instructor in charge of IT certification courses should be certified or pass the certification exam to teach that course. Another issue that can be addressed is the integration of the certification exam as part of the final assessment of the course. Currently, neither Cisco nor community colleges require from the student taking the certification exam in order to complete the course. However, to be a Cisco Certified Academy Instructor (CCAI), the instructor must take Cisco training as well as pass the industrial certification exam. It is recommended to make the certification exam as part of completing the course. This provides motivation and quality assurance across the curriculum.

\section{Conclusion}

This paper introduced some IT certificates which can be integrated into undergraduate IS curricula. The objectives of each certificate were examined and mapped into core courses from the IS 2002 model curriculum. Three potential certification tracks were identified: Networking, Programming, and IT hardware and software. A thorough investigation of a number of well-known IT certificates led to the identification of certificates which can be integrated in those tracks. For 
the Networking track, MOS, Network+, CCNA, i-Net+, and possibly CCNP certificate objectives can be mapped into 5 IS courses. For the programming track, MOS, SCJP, SCJA, and Linux+ certificate objectives can be integrated into other 4 IS courses. For the IT hardware and software track, MOS, A+, i-Net+ and Linux+ certificate objectives can be integrated into 4 courses of the IS curriculum. Furthermore, the Project+ certificate can be integrated into the project management course in the IS curriculum. The selection of the IT certificates for each track was optimized to facilitate student learning and the completion of the certificate. Moreover, textbooks and reference books required for courses that integrate IT certification objectives were identified. The cost of taking each certification exam and the number of exams required for each certificate were also identified to help students and administrators account for the additional costs. From an academic point of view, IS programs should be redesigned to educate students on how to adapt to rapid technological changes instead of training students in how to use particular tools. Preparing undergraduate students for certification can help address this paradigm shift. Employers often argue that recent IS graduates lack skills required in "real world" situations and basically support the idea of including IT certification in IS programs. Academics on the other hand argue the need for a broad and balanced education and do not see a need to include IT certification. A reasonable balance can be found between industry needs and academic requirements by integrating various IT certification tracks into the IS curriculum.

\section{References}

Andrews, J. \& Beck, W. (2005). i-Net+ Guide to the Internet (3rd ed.). Course Technology.

Cannon, K. (2003). Lab manual for CCNA Guide to Cisco networking (2nd ed.). Course Technology.

Cantor, J. (2002). Skills certifications and workforce development: Partnering with industry and ourselves [Electronic version]. Leadership Abstracts 15 (1). Retrieved January 24, 2005, from http://www.league.org/publication/abstracts/leadership/labs0102.html

Computing Curricula: Information Technology Volume. (2005). http://www.acm.org

Conrad, J. (2002). Server+ Guide to advanced hardware support. Course Technology.

Dean, T. (2004). Network+ Guide to networks ( $3^{\text {rd }}$ ed.). Course Technology.

Deitel, H. \& Deitel, P. (2005). Java how to program (6 $6^{\text {th }}$ ed.). Prentice Hall.

Eckert, J. \& Schitka, J. (2005). Linux+ 2005 in depth. Course Technology.

Farrell, J. (2006). Java programming ( $3^{\text {rd }}$ ed.). Course Technology. Retrieved from http://www.course.com

Gorgone, J., Davis, G., Valacich, J. , Topi, H., Feinstein, D. \& Longenecker, H. (2002). IS 2002: Model curriculum and guidelines for undergraduate programs in information systems. Retrieved November 29, 2005 from, http://www.acm.org/education/is2002.pdf

Grice, M. (2004). Lab manual for Network+ Guide to networks (3 ${ }^{\text {rd }}$ ed.) Course Technology. Retrieved from http://www.course.com/networking/

Groth, D. \& McGee, D. (2002). i-Net study guide. Sybex.

Koziniec, T., \& Dixon, M. (2002). ICT industry certification: Integration issues for post-secondary educational institutions in Australia. Proceedings of the 2002 Informing Science and IT Education Conference (InSITE),Cork, Ireland, pp.831-838. http://proceedings.informingscience.org/IS2002Proceedings

Montante, R., \& Khan, Z. (2001). Specialized certification programs in computer science. SIGCSE, Charlotte, NC, 371-375.

Hudson, K., Caudle, K., \& Cannon. K. (2003). CCNA guide to Cisco networking (2nd ed.). Course Technology.

Mughal, K. \& Rasmussen, R. (2000). A programmer's guide to Java certification. Addison-Wesley. 
Ortize, A. (2003). Preparing undergraduate students for Java certification. OOPSLA '03, Anaheim, California, October 26-30, 178-183.

Peterson, M., Morneau, K., \& Saad, A. (2003). Preparing the new information technology professional in Virginia, CITC4'03, Lafayette, IN, October 16-18, 28-30.

Randall, M., \& Zirkle, C. (2005). Information technology student-based certification in formal education settings: Who benefits and what is needed. Journal of Information Technology Education, 4, 287-306. Retrieved from http://jite.org/documents/Vol4/v4p287-306Randall78.pdf

Shelly, G., Cashman, T., Pratt, \& Last (2006). Microsoft Office Access 2003: Comprehensive concepts and techniques. Course Technology.

Tripp, L. (2002). Software certification debate: Benefits of certification. IEEE Computer, 35(6), 31-33.

Tucker, A., Deek, F., Jones, J., McCowan, D., Stephenson, C., \& Verno, A. (2003). A model curriculum for K-12 computer science: Final Report of the ACM K-12 Education Task Force Curriculum Committee, October 22. Retrieved from http://www.acm.org/education/k12/

Zeng, F. (2004). A new approach to integrate computer technology certifications into computer information system programs, Proceeding of the 2004 ASEE Annual Conference and Exposition, Salt Lake City, Utah, June 20-24. Retrieved from http://www.asee.org

\section{Biographies}

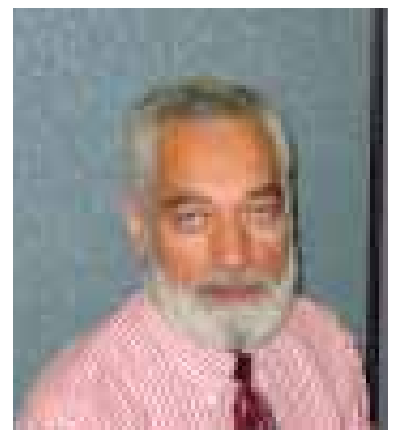

Akram Al-Rawi is a Professor of CIS at Zayed University, UAE. He has worked at several academic institutions of which the last two were the University of Missouri-Columbia and Columbia College, MO. His teaching interests include programming languages, logic design, and computer architecture. His research interests include computer simulation, web-caching architecture, and curriculum design. He holds certifications in A+, Network+, Sun Certified Java Programmer, ICDL, iNet+ and CCNA Intro.

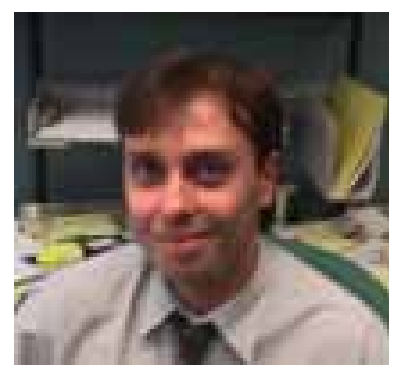

Azzedine Lansari received a $\mathrm{PhD}$ in Biomedical Engineering from North Carolina State University in 1992. From 1992-1998, he was a senior researcher at MANTECH, NC. He joined Zayed University in August 1998. Currently he is an assistant professor of Information systems. His research interests include systems modeling, educational technology and curriculum design in Information Systems. His teaching interests include instructional technology and statistical modeling.

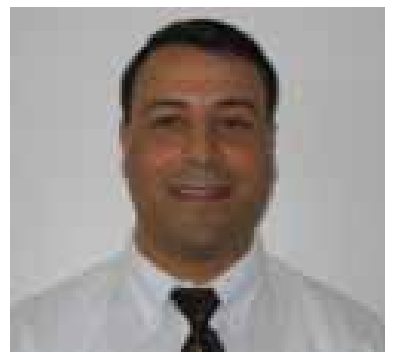

Faouzi Bouslama received a $\mathrm{PhD}$ in Electronics Engineering from Shizuoka University, Japan, in 1992. From 1992-1994, he was a researcher at Toshiba Co., Tokyo. From 1994-2000, he was Associate Professor of Information Systems, Hiroshima City University, Japan. He joined Zayed University, UAE, in August 2000. Currently, he is a Professor of Information Systems, Zayed University, UAE. His research interests include Neuro-fuzzy modeling and control, Signal processing, and IS curriculum design and development. 